\title{
MODELOS MATEMÁTICOS PARA ESTIMATIVA DA ÁREA FOLIAR DE MUDAS DE MAMOEIRO UTILIZANDO DIMENSÕES LINEARES
}

\author{
Thainá de Jesus Ambrosio ${ }^{1}$ \\ Karina Tiemi Hassuda dos Santos ${ }^{2}$ \\ Omar Schmildt ${ }^{3}$ \\ Edilson Romais Schmildt ${ }^{4}$
}

Resumo: Objetivou-se por este trabalho estimar a área foliar folhas de mamoeiro (Carica papaya L.) CV. Golden THB por meio de dimensões lineares do comprimento $(C)$ e largura $(L)$ de folhas e selecionar a equação que melhor representa a área foliar. Foram avaliadas 755 folhas, em mudas de aproximadamente $12 \mathrm{~cm}$, coletadas entre março e junho de 2016, produzidas em tubetes de $50 \mathrm{~cm}^{3}$ de substrato Bioplant $囚$, no município capixaba de Linhares. A área foliar observada (AFO) foi obtida usando o escaneamento das imagens e leitura no programa Image $\AA^{\circledR}$. Utilizou-se 700 folhas para a estimação das equações por modelos lineares e não lineares usando $C, L$ ou $C L$ como variável explicativa e, AFO como variável resposta. $A$ escolha da equação que representasse a área foliar em função das dimensões foliares baseou-se nos coeficientes linear e angular da regressão linear simples entre a área foliar estimada por cada equação obtida e, a AFO, usando 55 folhas. A equação que melhor representa a área foliar em mudas de 'Golden $T H B^{\prime}$ é $A F E=0,50893 C^{1,9926}$.

Palavras-chave: Carica papaya L.; Não-destrutivo; Regressão.

\footnotetext{
${ }^{1}$ Agronomia/Universidade Federal do Espírito Santo/Centro Universitário Norte do Espírito Santo, Brasil. E-mail: tatidro@gmail.com.

${ }^{2}$ Agronomia/Universidade Federal do Espírito Santo/Centro Universitário Norte do Espírito Santo, Brasil. E-mail: karina.hassuda@outlook.com.

${ }^{3}$ Agronomia/Universidade Federal do Espírito Santo/Centro Universitário Norte do Espírito Santo, Brasil. E-mail: omar-schmildt@ig.com.br.

4 Agronomia/Universidade Federal do Espírito Santo/Centro Universitário Norte do Espírito Santo, Brasil. E-mail: e.romais.s@gmail.com.
} 